\title{
A Contrastive Study of Street Furniture Design Between Paris and Chengdu City*
}

\author{
Tan Wang \\ College of Landscape Architecture \\ Sichuan Agricultural University \\ Chengdu, China
}

\author{
Xuhui Tang \\ College of Landscape Architecture \\ Sichuan Agricultural University \\ Chengdu, China
}

\author{
Xiaofang $\mathrm{Yu}^{* *}$ \\ College of Landscape Architecture \\ Sichuan Agricultural University \\ Chengdu, China \\ **Corresponding Author
}

\begin{abstract}
Street furniture, which directly demonstrates the characteristics of a city, is also an important carrier of urban culture. However, under the impact of the globalization wave, the new-built streets often lose the local environmental humane characteristics. The disappearance of regional cultural characteristics in the city will obviously weaken the street's beauty. Street Furniture in Chengdu changes quickly, and the quality of some is not high. Problems like they are few, scattered and lacking in professional design and so on, are affecting the overall image of urban street landscape. At the same time, because the street furniture design in Paris is recognized as a model, it provides a reference for Chengdu street furniture design.
\end{abstract}

Keywords—Chengdu; Paris; street furniture design

\section{INTRODUCTION}

With the development of urban level in China, the urban and street landscape design has undergone changes. Street furniture becomes the public facilities that serve the citizens from now, as the "furniture" shared by the people around them. Whether in the urban construction or in the improvement of residents' life, it is very important. Street furniture also begins to be a bridge communicating between people and living environment, which embodies a unique cultural background of the city. The famous architect Saarinen said: "Let me look at your city and I can tell what this city dweller is pursuing in culture [1]."

City street furniture in Chengdu changes with each passing day. Some quality is not high, there are few, scattered, lack of professional design problems, affecting the overall image of urban street landscape. At the same time, the street furniture design in Paris as a model, it provides a reference for urban street furniture design reference.

*Fund Project: Project Guangdong provincial science and technology project (2017B090907001)

\section{DEFINITION OF STREET FURNITURE}

The concept vocabulary of "urban street furniture" was produced in the 60's, English as "street furniture", and the direct translation is "street furniture". The term "Urban Element" in Europe can be referred to as "City accessory". And in Japan is often interpreted as "pedestrian road furniture", also known as "Street." In China, it is commonly referred to as a "public Environment Facility" [2].

Street furniture refers to a wide range of facilities, such as street seats, telephone booths, shelters, parking spaces, which are conveniently located on the streets for people to live in. Street furniture is public-facing, and service the public, regardless of the form of existence, its display is the public aesthetic taste and artistic pursuit, and the fundamental purpose of implementation is to reflect a city's public spirit.

\section{CHARACTERISTICS OF STREET FURNITURE}

\section{A. Features of Chengdu Street Furniture}

Chengdu is one of the first batches of historical and cultural cities published by the State Council. The discovery of Jinsha ruins has been traced back to the history of Chengdu's City of construction years ago. In recent years, in order to create a unique urban image of Chengdu, to resist the negative impact of globalization and the disappearance of regional characteristics, people have put forward a variety of suggestions and ideas. Otherwise, the relevant government units and designers have done a lot of efforts. Some of them are success, and others failed.

Chengdu is the same as other ancient cities in the world. In the thousands of years of development, through the wind and rain, it suffered much serious damage. Most of the ancient city of civilization in this process has not continued to develop, or even disappear. In recent years, Wenshufang, Daci Temple, Kuanzhai Alley historical and cultural areas 
have been transformed, increasing the tourist attractions in Chengdu, to bring more economic benefits. But by the natural, human environmental has an impact of the formation of regional cultural characteristics. In such a transformation, some buildings have been weakened, in particular, the original streets and houses in Daci Temple, a historical and cultural areas, were almost demolished, leaving only some of the better-preserved single-building buildings, which were questioned by many experts and people.

\section{B. Features of Paris Street Furniture}

Paris, the capital of French, is one of the largest cities on the European continent, known as the "cultural and artistic capital", "the romantic capital". As a world-renowned metropolis, from the mid of the 19th century famous Ottoman program to contemporary Sarkozy's grand Paris plan, there is no place to reflect the spirit of the city of Paris and the cherish that Parisian people regard the quality of urban public environment. A poet once praised the public space as "the extravagance of all".

The beautiful city needs the beautiful street furniture to render. If only there is the practical value but not the design, this city must appear mediocre and uninteresting. Paris planned and designed the street furniture, and probably it's the earliest in the world's cities. In the middle of the 19th century, Baron Osman was instructed to promote the new Metropolitan Paris Project, and he invited a lot of wellknown architects to design a series of unique new street furniture in neoclassical style, including newsstand, street lights, public seats, pedestrian bollards. After 18 years of transformation, Paris has been transformed. Today's view of these hundred years of street furniture is still the first class. "Even after this street furniture has been damaged for years, the design of the new designers continues the Osman-style concept and style, which is like the best heroine, leading the landscape of Paris. Now it seems that the furniture of old and new streets is still well blended," said Dr Nanyu, of the School of Architecture and urban planning at Tongji University [3]."

\section{The PRESENT SituAtion OF StREET FuRniture}

\section{A. The Present Situation of Chengdu Street Furniture}

Chengdu is an ancient cultural city with a history of 4,500 years of civilization. The long history has given birth to the brilliant ancient Shu civilization and profound influence of regional culture. Today, the culture of Chengdu is not only the continuation of Mianyuan history and culture, but also the basis of the rise of modern culture, which is full of vitality and carefree flexibility. Chengdu is an immigrant city, bringing the customs and culture together, forming a unique urban spirit. In the long river of history, Chengdu Culture has shown a harmonious and inclusive cultural tolerance, the spirit of pioneering and innovative cultural, the cultural tradition of Chongwen re-teaching and other characteristics.

There are three main problems in the design of street furniture in Chengdu:
1) The form of modernism design is the same: Some foreign well-known furniture designers' design works were blindly introduced, that appeared in the streets of Chinese cities. This street furniture tends to be similar in the function, shape, and the choice of materials so that people can see the same furniture all over the world. And the streets of Chinese cities and street furniture have a feeling that I've seen in other place.

2) Function, modelling, material selection and use that are not fitable: At present, a lot of urban street furniture blindly pursuits of formal aesthetics, material special, and functional peculiar, but neglected the use of the main point of furniture--people. The result is that the street furniture is mostly a kind of decoration, and the use rate is not high, resulting in the waste of resources;

3) The style and contemporary social culture do not coordinate: Some street furniture ignores local culture, the inheritance and development of historical context, and abandons the exploration of Chinese historical and cultural connotation. The historical sense and time of the humanistic environment are diluted by the tendency of unification and similarity. This is a misunderstanding of the design of urban public facilities.

\section{B. Status of Street Furniture in Paris}

The street furniture design of the Champs Elysees in Paris is one of the most representatives. However, the Champs Elysees was not so more than 10 years ago, when the sidewalk environment is very poor, what kind of street is piled into the streets, passers-by difficult. With Urban space quality become worse and business gradually depressed, the world famous brands had to move away. Chirac, the mayor of Paris, was determined to transform the boulevard into "the most beautiful commercial promenade in the world". So the street furniture back to the main role of the throne, increased the number of open-air coffee and large sycamore trees, the bus station in both sides completely with transparent materials, the night reflected around the colorful window, street lights, advertising lights, such as crystal bottle-like clear exquisite. The statue of a modern street art master is lined up, and the Champs Elysees is like an open-air gallery.

The main advantages of Paris Street Furniture design:

1) Design is modern and novel: Whether then or now, Paris street furniture design is a minimalist symbol design, there is a modern it will never be outdated, to the entire city of Paris has brought a hint of retro-vintage feeling.

2) Artistic design: In the streets of Paris, there are colorful rolling poster pavilion facilitates which add a touch of bright colors to the streets.

3) Complex design: Much street furniture in Paris is unique in ergonomics, such as flower beds, slabs, sinks, etc. They are combined with settee, which are concise and beautiful, and convenient for the public. Paris city street furniture design often combines several functions.

4) Exquisite craftsmanship: The streets of Paris street furniture, whether indirect or complex, its materials and 
crafts are very delicate. Most of the street furniture with high-efficiency functions, exquisite technology and postmaintenance, which formed a sharp contrast to the city of Chengdu Street Furniture situation.

\section{PARIS StREet FURNITURE DESIGN ENLIGHTENMENT TO CHENGDU}

Paris street landscape to Chengdu street furniture design has the following five inspirations:

\section{A. The Principle of Functionality}

The fundamental principle of design is the functional nature of street furniture. If there is no seat for rest and trash cans on a street, the street furniture is not complete. Excellent street furniture not only allows people to enjoy the material, but also to get spiritual pleasure.

\section{B. The Principle of Durability}

Because of long-term open-air placement and frequent used about street furniture, on the one hand, we need to consider its from, morphological structure and material considerations, on the other hand, we need to consider human vandalism and post-maintenance. It's vital to test the rationality and scientificity of design for durability.

\section{The Principle of Humanized Design}

Human are both the hero of the city and the user of street furniture. Therefore, in the design of street furniture, we should think over about people's psychological and physiological needs.

\section{The Principle of Formal Beauty}

The law of form beauty is the fundamental principle of creating the overall aesthetic sense of urban environment. Street furniture Design, as a part of the urban environment, should also abide by this law. Ma Qingzhong said: "We call this kind of functional appliances for public works of art, because it embodies the specific city people's aesthetic taste, personality tendencies, regional characteristics, and the concept of urban culture and spirit, which guides cool sexual behavior, pleasure, experiences the aesthetic sense of place" [4]. Street furniture design should be created by our own, to touch people's hearts, and to give people visual and psychological satisfaction.

\section{E. The Principle of Wholeness}

Street furniture needs to consider the harmony with the surrounding environment, together consist of a whole, at the same time, and also need to be unified. Regardless of the facilities size, they should be interactive, interdependent, reflecting the overall unity of the characteristics [5]. Therefore, the street furniture, no matter of their size, needs to be integrated, interdependent, reflecting on their own personality in the overall and unity.

\section{CONCLUSION}

As one of the elements of urban space, street furniture is an indispensable part of urban image construction. Street furniture is closely related to the daily life of the public. On the basis of realizing its own function, it reflects the characteristics and style of the city along with the building, and also embodies the quality of the citizens' life, and transmits the cultural and artistic information of the city. We also expect this street furniture can be able to achieve the original vision of the designers: it can both provide the convenience for the public, and also fully integrated into Chengdu culture, to become a feature of the scene in Chengdu Street.

In a word, street furniture should be closely linked with urban planning, street landscape and so on. From the overall planning, combining the street furniture with local characteristics and cultural heritage, we can construct the street furniture which meets the function and enhance the overall image of city. As the detail of the street furniture of Paris, France has been more interesting and urban charm. It is an important factor to create its characteristic livable city in Chengdu urban street furniture design.

\section{REFERENCES}

[1] Chalinin. Qiyuan Gu. City-its development, decline and future [H] BEIJING, China Architecture and building Press, 1986

[2] Xin Feng. Public Environment Facility design [M]. Shanghai: Donghua University Press, 2016

[3] Nanyu Street Furniture: Detail description City grade forest [OL] Global Times, 2009

[4] Wang Yu. Design of urban environmental facilities [M]. Shanghai: Shanghai Publishing House, 2006

[5] Machin. Basic theory of public art [M]. Tianjin: Tianjin University Press, 2008 